\title{
A field test of the relationship between habitat area and population size for five perennial plant species
}

\author{
Hans Henrik Bruun
}

Bruun, H. H. 2005. A field test of the relationship between habitat area and population size for five perennial plant species. - Web. Ecol. 5: 1-5.

\begin{abstract}
The population sizes of five perennial vascular plant species confined to old unimproved dry grasslands were assessed, viz. Anthericum ramosum, Filipendula vulgaris, Silene nutans, Thymus pulegioides, and Thymus serpyllum. All populations within the region were included. Only for Filipendula vulgaris and Thymus serpyllum, significant relationships between habitat area and population size were found. Thus, apparently perennial vascular plants have a limited ability to respond to large habitat areas by forming large populations. This puts a question mark on the use of incidence-function models for the study of plant metapopulations, because these models are based on an assumed positive relationship between habitat area and population size.
\end{abstract}

H. H. Bruun (hans_henrik.bruun@ekol.lu.se), Lund Univ., Dept of Ecology, Section for Plant Ecology and Systematics, Ecology Building, SE-223 62 Lund, Sweden.

Empirical studies of metapopulation dynamics (Hanski 1999) have gained considerable momentum over the past decade. Parallel to this, there has been much debate about the applicability of the concept of the metapopulation to plants and many empirical studies (e.g. Freckleton and Watkinson 2002, Bullock et al. 2002, Ehrlén and Eriksson 2003, Ouborg and Eriksson 2004). Two of the most important reasons for interest in metapopulations, both in general and for plants in particular, have been the apparent suitability of the metapopulation concept to conservation efforts in landscapes with increasingly fragmented habitats, and the development of practically applicable metapopulation models. While some models require population censuses in each population (e.g., Akçakaya 2001), one of the less data demanding, and therefore more popular, methods is the incidence function model (Hanski et al. 1996, ter Braak et al. 1997). This type of metapopulation model allows for the simplifying assump- tion that extinction probability increases linearly with decreasing habitat area. Making this assumption allows one to replace laborious population censuses with the incidence, i.e. presence or absence, of the focal species from each patch of suitable habitat.

The assumption of a habitat area-extinction probability relationship has the following rationale: 1) extinction risk must increase with decreasing population size, at least below a certain threshold (Barrett and Kohn 1991, Ellstrand and Elam 1993, Fischer and Stöcklin 1997, but see Husband and Barrett 1996), and 2) population size is likely to decrease with decreasing habitat area. Assumption 2 is justified if populations respond immediately to changes in resources, and if no dispersal limitation exists (Ouborg and Eriksson 2004). Therefore, it applies better to fast-reproducing (and short-lived) and highly motile organisms, than to long-lived sessile organisms. Most vascular plants are found in the latter end of this continuum. Species con- 
fined to natural and semi-natural habitats of conservation interest often have strong propensities to form remnant populations (Eriksson 1996).

The present paper aims at testing whether population size for five perennial vascular plant species inhabiting Scandinavian grassland patches is well predicted by habitat patch area.

\section{Materials and methods}

\section{Study area}

The studied area $\left(483 \mathrm{~km}^{2}\right)$ is situated on the island Zealand (Sjælland) in eastern Denmark $\left(12^{\circ} \mathrm{E}, 55^{\circ} 45^{\prime} \mathrm{N}\right)$. The climate is temperate (mean annual temperature $7.7^{\circ} \mathrm{C}$; mean annual precipitation 500-600 mm). Semi-natural grasslands occur scattered throughout the area. They mostly occur on areas inaccessible to agriculture due to topography, i.e. often on steep slopes, mainly fixed coastal slopes from the Littorina sea transgression. Another important group of patches constitute Bronze-age burial mounds, which are circular vaulted mounds $5-15 \mathrm{~m}$ in diameter and 2-5 m high, originally built of sods (Holst et al. 1998). Grazing has ceased on most burial mounds in the 1930s due to a general protection act, whereas it has continued until around 1970 or later on all other grassland sites.

\section{Assessment of population size}

The species composition in 97 sites of old unimproved semi-natural grassland, comprising all available sites within the study area, was investigated in the summers 1996-1997 (Bruun 2000a). Species also occurring frequently in other habitats were identified by use of three external data sets: 1) a data set of species observed during the field survey at other sites than old grasslands, 2) a data set on ground floor species in deciduous forest in the same region (Graae and Sunde 2000), and 3) data on species from road verges in the island of Sjælland (Hansen and Jensen 1972). The deletion of these generalist species left 76 perennial herbaceous grassland specialist species out of a total of 210 species. Of these five species were selected so as to differ as much as possible on the number of habitat patches occupied. The same species were subjected to population genetic studies (Rosquist and Prentice 2000, Weidema et al. 2000, unpubl.), so the final selection of species was based on their suitability to allozyme electrophoresis. For these species, Anthericum ramosum L., Filipendula vulgaris Moench, Silene nutans L., Thymus pulegioides L., and Thymus serpyllum L., population size (adult plants) on each occupied habitat patch was estimated, for small populations by simple counts, for large populations by extrapolating counts on unit area to the occupied area within the grassland patch as estimated us- ing measuring bands. The total area of grassland patches was estimated from the digitised polygons using geographical information systems. Based on the focal species' occurrence in classes of soil acidity and water availability in a large external data set (2133 records of vegetation and local environment in Danish grasslands and related communities) and on the range of measured soil acidity and water availability at each of the focal grassland site, all five species were expected to occur potentially in all 97 sites (data from Bruun 2000b).

Relationships between patch area and population size of each of the five species, with all variables subjected to logarithmic transformation, was sought for by two different methods: conventional linear regression and partitioned regression (Thomson et al. 1996). Initial visual inspection of the bivariate double-log scattergrams (Fig. 2) showed an apparent ceiling, i.e. that $\mathrm{y}<\mathrm{a}^{*} \mathrm{x}$, where $\mathrm{y}$ is $\log$ population size, $\mathrm{a}$ is a constant, and $\mathrm{x}$ is patch area. Thus, population size is constrained to low values at small sites, whereas it can take a broader range of values at large sites. Partitioned regression was used in an attempt to parameterize this ceiling. It was done by first fitting a regression line through the entire point cloud by linear least-squares regression, then dividing the data into two subsets according to the sign of their residuals, and then to repeat that procedure within the subsets.

\section{Results}

The five species investigated exhibit highly varying regional abundance; $F$ vulgaris occurs at 61 sites, $T$. pulegioides at 23, T. serpyllum at 17, S. nutans at 11 , and $A$. ramosum at 8 sites (Fig. 1). Scatterplots of population size versus patch area seemed in all five cases to have a ceiling. In other words small sites supported only small populations, whereas large sites could support populations of any size. However, linear regression only showed a response of population size to patch area in the cases of $F$. vulgaris $\left(\mathrm{y}=0.61 \mathrm{x}-0.08 ; \mathrm{r}^{2}=0.34 ; \mathrm{F}=30.8 ; p<0.001\right.$ ) and T. serpyllum ( $\mathrm{y}=0.56 \mathrm{x}-1.20 ; \mathrm{r}^{2}=0.35 ; \mathrm{F}=8.13 ; p=$ 0.012 ) (Fig. 2). In addition, partitioned regression analysis detected an apparent ceiling for T. serpyllum $\left(\mathrm{r}^{2}=0.63 ; \mathrm{F}=\right.$ 8.61; $p=0.033$ ) (Fig. 2). For the other three species, no significant relationships were found. In the case of $T$. pulegioides an outlying data point above the ceiling was removed, but that did not change the regression result. Likewise, for $S$. nutans an outlier representing a population of a few individuals in a very large grassland site was removed, but again it did not change the results.

\section{Discussion}

Relationships between population size and habitat area were found for F. vulgaris and T. serpyllum. Thus, only two 

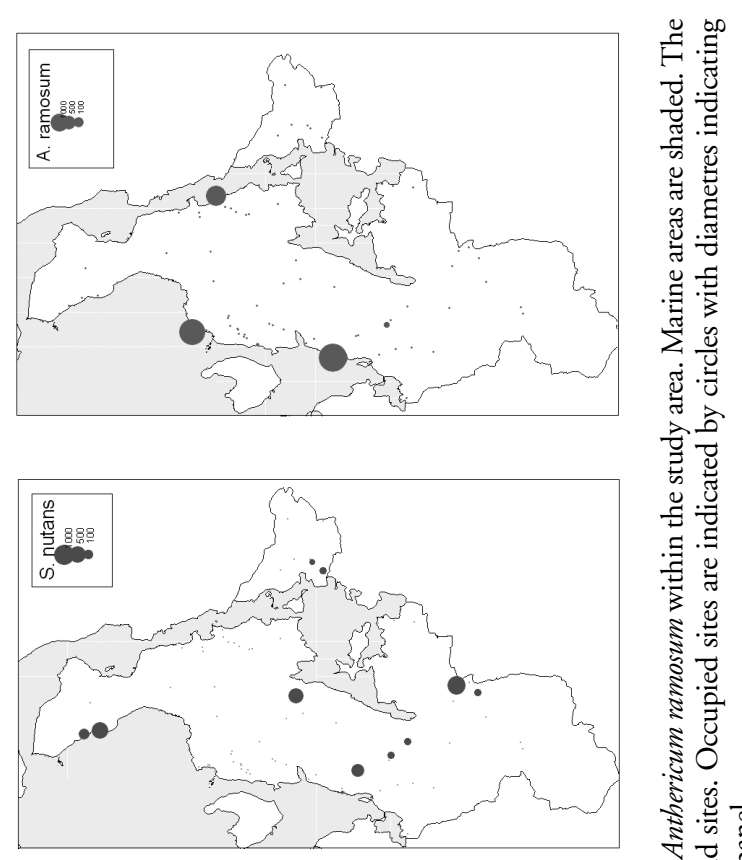

总

.
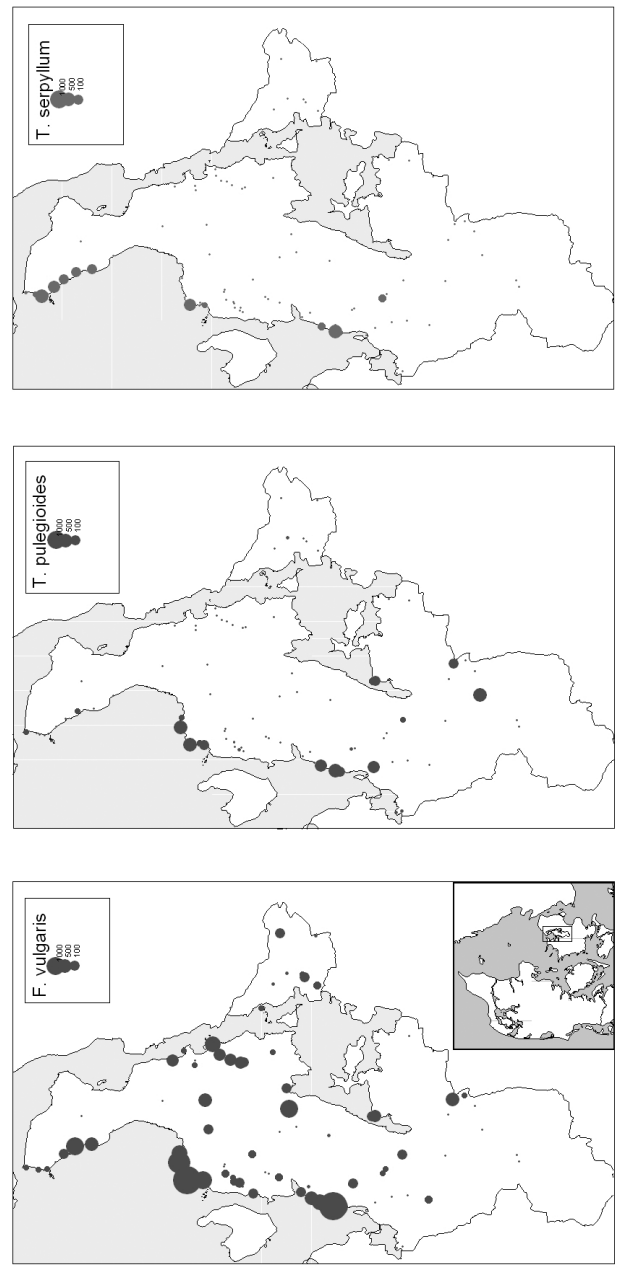

总
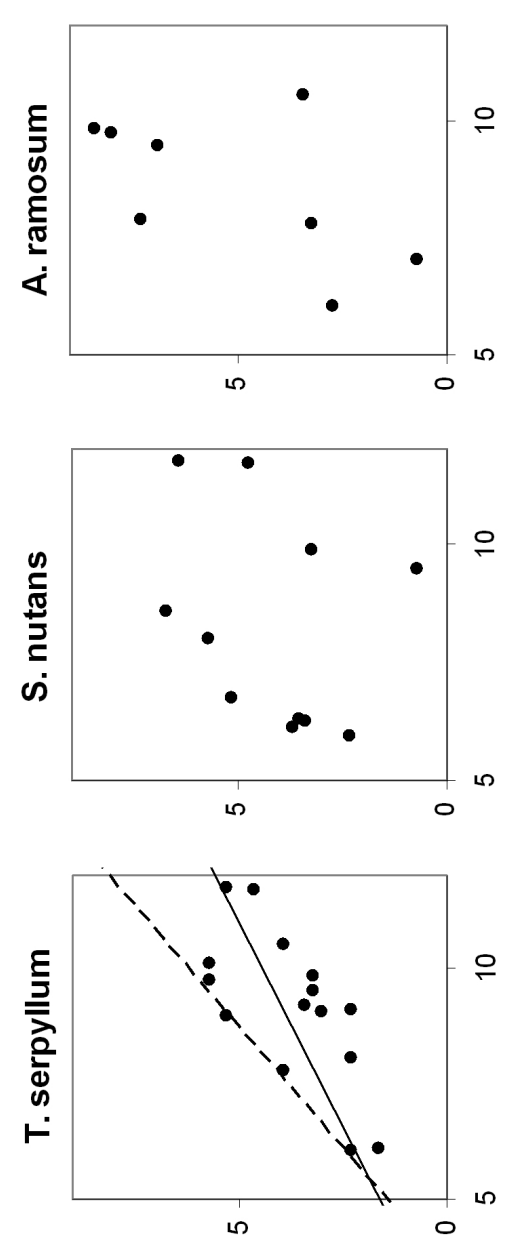

$\frac{\sigma}{ \pm}$
$\frac{0}{\sigma}$
$\frac{\pi}{\pi}$
$\frac{ \pm}{\sigma}$
$\frac{1}{1}$
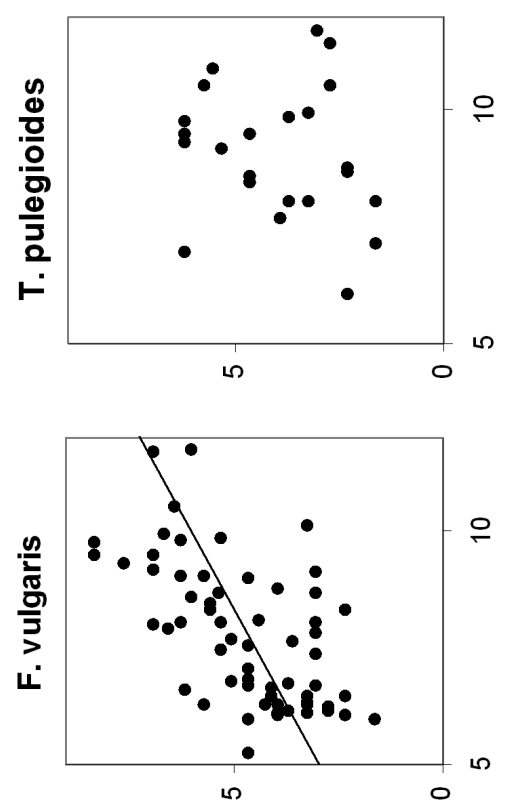

әz!̣s uo!jejndod

H

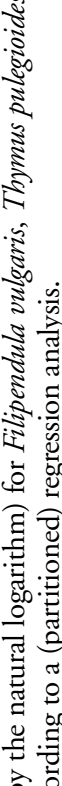

च

(1) 氙

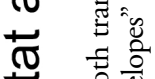

을

矛递

돌.

氜

고ำ

.

覀

急

를

岁

岁.马

.

हैं

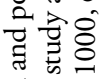

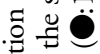

㟧.

它. 递兽
ปั

政

焉

ำ है 
out of five investigated species seem to be able to respond to large habitat areas by forming large populations. Jacquemyn et al. (2002) found a significant relationship between forest area and population size for the forest herb Primula elatior. However, if the results of the present investigation apply more generally, a fundamental assumption of incidence function models is not met with. This shed doubt on their general applicability (contrary to Hanski 1999) and on empirical studies of plant metapopulations (e.g. Quintana-Ascencio and Menges 1996). All five species are long-lived perennials with moderate reproductive output. Yet, they seem to differ in one or more vital attributes, which might be potential population growth rate. Alternatively, variation among the species in other attributes might explain results, e.g. dispersal ability and niche breadth. These will be discussed in turn.

The dispersal among habitat patches should not influence the relationship between population size and habitat area. However, dispersal within habitat patches may well be limited (Ehrlén and Eriksson 2000), and the effect of such dispersal limitation on population size should increase with habitat area. Dispersal ability and potential population growth rate are probably both governed in part by population-level reproductive output. Thus, the regionally and locally most abundant species should also be expected to have the highest ability to disperse into empty habitat. Filipendula vulgaris was the most abundant of all grassland specialist species within the study area, occurring in $67 \%$ of the sites. This is similar to observations in central Sweden reported by Eriksson and Kiviniemi (1999). In addition, F. vulgaris had larger local populations (two populations consisting of ca 4000 individuals) than did $T$. pulegioides, T. serpyllum (both up to 500 individuals), and $S$. nutans (up to $>800$ individuals). However, $A$. ramosum also had large local populations (maximum 4500 individuals), but was regionally sparse, thus contradicting the pattern of local and regional abundance being related. In contrast to the other investigated species, $A$. ramosum is close to its northern distribution range in the study area. This may cause seed production and/or recruitment to be hampered by climate in some, if not most, years (Pigott 1992, Jump and Woodward 2003). These population processes were not investigated in the present study, however.

Niche breadth and potential population growth rate could probably be linked. If the local environment in the grassland patches would fit suboptimally to the persistence niche or the regeneration niche of a species, population growth would be halted. The five study species are all grassland specialist species, and according to a modelling approach based on soil $\mathrm{pH}$ and potential insolation they all should have the potential to inhabit all investigated grassland patches (Bruun 2000b). However, a more accurate model, or sowing experiments, might identify environmental gradients than those mentioned along which the grassland patches would vary. In any case, the total diversity of grassland specialist plant species is higher in the northern part of the study area for reasons of both presentday landscape configuration and land-use history back to the Iron Age (Bruun et al. 2001).

Among the investigated species, the relationship between patch area and population size appeared to be stronger for more frequent species. Thus, perhaps too few data points were available to detect a relationship for the less frequent species. There is no doubt that a lower detection limit exists, but $T$. pulegioides with 23 sites was clearly above it and still showed no significant relationship, and 11 and 8 sites for $A$. ramosum and $S$. nutans, respectively, should also be enough if the patch area-population size relationship was strong. Moreover, incidence function metapopulation models are mainly of interest to practical conservation of plant species that are scarce. Thus, plant metapopulation studies cannot escape the problem of small sample size for infrequent species, even at investigation scales similar to the present (ca $500 \mathrm{~km}^{2}$ ).

In conclusion, it is not justified to assume a positive relationship between habitat area and population size for all these grassland species, and probably not for perennial plants in general. This challenges uncritical usage of incidence models to investigate plant metapopulations, but not the idea that plants may form metapopulations.

Acknowledgements - I am deeply indebted to Inger Weidema, Line Magnussen and Gabrielle Rosquist for access to population census data.

\section{References}

Akçakaya, H. R. 2001. Linking population-level risk assessment with landscape and habitat models. - Sci. Total Environ. 274: 283-291.

Barrett, S. C. H. and Kohn, J. R., 1991. Genetic and evolutionary consequences of small population size in plants: implications for conservation. - In: Falk, D. A. and Holsinger, K. E. (eds), Genetics and conservation of rare plants. Oxford Univ. Press, pp. 3-30.

Bruun, H. H. 2000a. Patterns of species richness in patches of dry grassland in an agricultural landscape. - Ecography 23: 641-650.

Bruun, H. H. 2000b. Deficit in community species richness as explained by area and isolation of sites. - Div. Distribut. 6: 129-135.

Bruun, H. H. et al. 2001. Plant species richness in grasslands: the relative importance of contemporary environment and land-use history since the Iron Age. - Ecography 24: 569578.

Bullock, J. M. et al. 2002. Plant dispersal and colonisation processes at local and landscape scales. - In: Bullock, J. M., Kenward, R. E. and Hails, R. S. (eds), Dispersal ecology. Blackwell, pp. 279-302.

Ehrlén, J. and Eriksson, O. 2000. Dispersal limitation and patch occupancy in forest herbs. - Ecology 81: 1667-1674.

Ehrlén, J. and Eriksson, O. 2003. Large-scale spatial dynamics of plants: a response to Freckleton \& Watkinson. - J. Ecol. 91: 316-320. 
Ellstrand, N. C. and Elam, D. R. 1993. Population genetic consequences of small population size. - Annu. Rev. Ecol. Syst. 24: 217-242.

Eriksson, O. 1996. Regional dynamics of plants: a review of evidence for remnant, source-sink and metapopulations. Oikos 77: 248-258.

Eriksson, O. and Kiviniemi, K. 1999. Site occupancy, recruitment and extinction thresholds in grassland plants: an experimental study. - Biol. Conserv. 87: 319-325.

Fischer, M. and Stöcklin, J. 1997. Local extinction of plants in remnants of extensively used calcareous grasslands 1950 1985. - Conserv. Biol. 11: 727-737.

Freckleton, R. P. and Watkinson, A. R. 2002. Large-scale spatial dynamics of plants: metapopulations, regional ensembles and patchy populations. - J. Ecol. 90: 419-434.

Graae, B. J. and Sunde, P. B. 2000. The impact of forest continuity and management of forest floor vegetation evaluated by species traits. - Ecography 23: 720-731.

Hansen, K. and Jensen, J. 1972. The vegetation on roadsides in Denmark. Qualitative and quantitative composition. Dansk Bot. Arkiv 28: 21-61.

Hanski, I. 1999. Metapopulation ecology. - Oxford Univ. Press.

Hanski, I. et al. 1996. The quantitative incidence function model and persistence of an endangered butterfly metapopulation. - Conserv. Biol. 10: 578-590.

Holst, M. K., Breuning-Madsen, H. and Olsson, M. 1998. Soil forming processes in and below a bronze age burial mound at Lejrskov, southern Jutland. - Dan. J. Geogr. 98: 46-55.

Husband, B. C. and Barrett, S. C. H. 1996. A metapopulation perspective in plant population biology. - J. Ecol. 84: 461469.
Jacquemyn, H., Brys, R. and Hermy, M. 2002. Patch occupancy, population size and reproductive success of a forest herb (Primula elatior) in a fragmented landscape. - Oecologia 130: 617-625.

Jump, A. S. and Woodward, F. I. 2003. Seed production and population density decline approaching the range-edge of Cirsium species. - New Phytol. 160: 349-358.

Ouborg, N. J. and Eriksson, O. 2004. Towards a metapopulation concept for plants. - In: Hanski, I. and Gaggiotti, O. E. (eds), Ecology, genetics, and evolution of metapopulations. Elsevier, pp. 447-469.

Pigott, C. D. 1992. Are species distributions determined by failure to set seed? - In: Marshall, C. and Grace, J. (eds), Fruit and seed production: aspects of environmental physiology and ecology. Cambridge Univ. Press, pp. 203-216.

Quintana-Ascencio, R. F. and Menges, E. S. 1996. Inferring metapopulation dynamics from patch-level incidence of Florida scrub plants. - Conserv. Biol. 10: 1210-1219.

Rosquist, G. and Prentice, H. C. 2000. Habitat fragmentation and the structure of genetic diversity within disjunct isolates of Anthericum ramosum L. (Anthericaceae) in Scandinavia. - Biol. J. Linn. Soc. 69: 193-212.

ter Braak, C. J. F., Hanski, I. and Verboom, J. 1997. The incidence function approach to modeling of metapopulation dynamics. - In: Bascompte, J. and Sole, R. V. (eds), Modeling spatiotemporal dynamics in ecology. Springer, pp. 167-188.

Thomson, J. D. et al. 1996. Untangling multiple factors in spatial distributions: lilies, gophers, and rocks. - Ecology 77: 1698-1715.

Weidema, I. R., Magnussen, L. S. and Philipp, M. 2000. Gene flow and mode of pollination in a dry-grassland species, Filipendula vulgaris (Rosaceae). - Heredity 84: 311-320. 